\title{
O MOVIMENTO PROGRESSIVO-REGRESSIVO NA DIALÉTICA UNIVERSAL E SINGULAR
}

\author{
Kátia Maheirie \\ Zuleica Pretto ${ }^{\star \star}$
}

\begin{abstract}
Resumo
Apresenta-se a contribuição do movimento progressivo-regressivo, desenvolvido por Sartre para a compreensão, por parte do pesquisador, do projeto-de-ser de um sujeito em situação. O movimento progressivo-regressivo refere-se à totalização histórica da singularidade na intersecção com a totalidade histórica geral, ambos imbricados, porém irredutiveis. Destaca para o pesquisador que a análise deverá ser dialética, caracterizada por sínteses constituidas a partir de contradições, alternando momentos de cumplicidade e de criticidade, compondo um momento da práxis, transformando tanto o objeto da pesquisa como o pesquisador, situando-os em sua condição objetiva e subjetiva de devir.

Palavras-chave: Movimento progressivo-regressivo em Sartre. Projeto de ser. Objetividade e subjetividade.
\end{abstract}

\section{THE PROGRESSIVE/REGRESSIVE METHOD IN THE SINGULAR AND UNIVERSAL DIALECTICS}

\begin{abstract}
We present the contribution of the progressive/regressive method, developed by Sartre, in order to the understanding of a project-of-being of a subject in a situation, made by a researcher. This project seeks for the historical totalization of singularity in its intersection with the general historical totalization, which are both intricate but irreducible. In this sense, the analysis shall be dialectic by alternating moments of complicity and criticality, which form a moment of praxis and transform both object and researcher, thus placing the object and researcher in their objective and subjective capacities.

Keywords: Progressive/regressive method in Sartre. Being project. Objectivity and subjectivity.

* Universidade Federal de Santa Catarina. Doutora em Psicologia Social pela Pontifícia Universidade Católica de São Paulo, PUC/SP. Campus Universitário. Trindade - CEP: 88010-970 - Florianópolis, SC.

E-mail:maheirie@cfh.ufsc.br

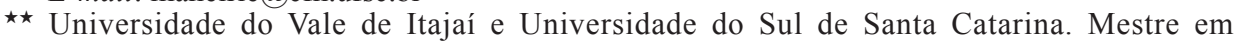
Psicologia pela Universidade Federal de Santa Catarina. Servidão Damázio, 305 Campeche - CEP. 88063-350 - Florianópolis-SC.

E-mail: zuleicapretto@yahoo.com.br
\end{abstract}




\section{A CONdição dialética do SUJEITo E dA HiSTória}

A verdadeira pesquisa intelectual, se pretende livrar a verdade dos mitos que a obscurecem, implica uma passagem pela singularidade do pesquisador. Este precisa se situar no universo social para capturar e destruir nele e fora dele os limites que a ideologia impõe ao saber. É no nível da situação que pode agir a dialética da interiorização e da exteriorização; o pensamento do intelectual deve se voltar todo o tempo para si mesmo, para se apoderar sempre como universalidade singular [...] é um trabalho dialético de um universal singular sobre universais singulares, e deve se fazer primeiro no concreto, depois no abstrato. (SARTRE, 1972/1994, p. 34-35).

Numa perspectiva histórico-dialética, o sujeito se constitui a partir das relações e, conseqüentemente, das mediações que estabelece com o mundo. Situado num contexto histórico específico, o sujeito está em meio a conflitos, contradições, negações, afirmações e superações, as quais estão impressas nas suas ações cotidianas, mediadas pela historia que se dá num movimento dialético - o movimento singular/universal. Isto é, o homem, em seu sentido genérico, se faz um sujeito singular/original, já que pode se fazer diferente do que a história fez dele, e se faz, ao mesmo tempo, um sujeito universal, já que contém a história da humanidade em si, e se encontra aberto a uma diversidade de possibilidades em curso.

A compreensão dialética, infere que o conhecimento provém da experiência concreta dos homens na cotidianidade como fruto das relações dos sujeitos com as coisas, com a cultura, com outros sujeitos e com o tempo (passado, presente e futuro pretendido). Desta maneira, a humanização é um processo que ocorre para além da realidade bruta, isto é, o processo de humanização significa a realidade, promovendo projetos individuais e coletivos e, consequentemente, produzindo sujeitos singulares e sociedades diversificadas que compõem a história humana.

Para compreender tal processo, o método dialético identifica-se com a problemática sobre a qual se debruça, buscando um caráter de atualização, de totalidade, de especificidade e de abertura e considera, assim, improdutivo tentar reduzir compreensões da realidade a explicações lógico-formais.

Dizer que o ser é dialético, é dizer inicialmente (no plano ontológico) que ele é uma totalidade que implica a afirmação e a negação. Em seguida (no plano antropológico), é dizer que o ser se realiza não apenas enquanto mundo natural, mas também e, fundamentalmente, como mundo histórico (ou humano). Desta forma, queremos dizer que o sujeito concreto aparece como sujeito livre histórico ${ }^{1}$, essencialmente temporal.

Adotar o método dialético, portanto, é,

[...] considerar que os homens, suas objetivações e seus trabalhos, as relações humanas, enfim, são o que há de mais 
concreto; pois uma primeira abordagem recoloca-os sem dificuldade em seu nível e descobre suas determinações gerais. Em uma sociedade de que conhecemos o movimento e os caracteres, o desenvolvimento das forças produtoras e as relações de produção, todo fato novo (homem, ação, obra) aparece como já situado em sua generalidade; o progresso consiste em esclarecer as estruturas mais profundas pela originalidade do fato considerado, para poder determinar em compensação esta originalidade do fato pelas estruturas fundamentais. Há um duplo movimento (SARTRE, 1960/1978, p. 133).

O que está na base da compreensão de Sartre é a concepção de práxis, a partir da perspectiva marxista, aplicada também no plano do sujeito singular, uma vez que a práxis envolve uma relação dialética entre o objetivo e o subjetivo:

Seria necessário mostrar a necessidade conjunta de 'interiorização do exterior' e 'exteriorização do interior'. A práxis, com efeito, é uma passagem do objetivo para o objetivo, através da interiorização; o projeto, como superação subjetiva da objetividade no sentido da objetividade, estendido entre as condições objetivas do meio e as estruturas objetivas do campo dos possíveis, representa em si mesmo a unidade movente da subjetividade e da objetividade, essas determinações cardeais da ação. O subjetivo aparece então como um momento necessário do processo objetivo (SARTRE, 1960/1978, p. 154).

Desse modo, o movimento progressivo-regressivo está fundamentado na noção de práxis singular, a qual se sustenta na noção de projeto que, ao fim das contas, é o que define, em Sartre, a constituição do sujeito singular/único.

\section{ONTOLOGia E PROJETo}

A ontologia sartreana entende que o sujeito não é ser em-si, o qual não precisasse estabelecer relação para existir, bastando-se por si mesmo, mas sim é ser para-si, ou seja, é por princípio liberdade, pois não está determinado no seu vira-ser como os outros animais. Por não estar determinado, é um projeto: não está pronto, está por se fazer, e ele será precisamente aquilo que fizer com aquilo que se fez dele. Num primeiro momento, viverá seu projeto espontaneamente, sem manter o eu posicionado frente a suas escolhas e seu agir. Apenas num segundo momento, a partir da reflexão crítica, poderá ter condições de assumir o projeto explicitamente. De qualquer modo, eleger um projeto, qualquer que seja ele, fazse uma obrigação ontológica para os sujeitos rumo à humanização.

Neste processo de elaboração de seu projeto ou de constituição de sua singularidade em meio a multiplicidade da coletividade, o sujeito precisa relacionar-se com o outro, ou seja, ser atravessado pelas condições históricas deter- 
minadas, e, ao fazê-lo, inicia o processo de subjetivação e objetivação de seu ser no mundo. É por isso que, conclui Sartre (1943/2001, p.453), "o fundamento do para-si é justamente a relação com o outro". A partir do outro - pessoa, objeto, racionalidade, corpo, tempo - que o sujeito apreende significados e sentidos para o mundo e para si, e, mais do que isso, é a partir dessa relação que é significado como um ser humano entre outros seres-humanos. Neste sentido, experimenta a alienação e a sensação de estar fora da história, como se esta fosse estranha a ele já que ela é escrita por outros também. Porém, é justamente a busca da superação dessa alienação, que faz com que ele se relacione com o mundo e se constitua ser-no-mundo, sendo esta a sua chance de fazer-se diferente do que fizeram dele (PRETTO, 2003).

Por ser projeto, o sujeito é definido por um futuro. Em outras palavras, ele se faz no presente, com base num passado e dirigido por um desejo, por aquilo que ainda não é e projeta vir a ser. Desse modo, transita a partir de um campo de possíveis sociais e históricos, por meio dos quais visa superar sua objetivação, por meio da subjetivação, em direção a uma nova objetivação (MAHEIRIE, 1994, 2002).

O campo dos possíveis sempre existe e não devemos imaginálo como uma zona de indeterminação, mas ao contrário, como uma região fortemente estruturada, que depende da história inteira e que envolve suas próprias contradições. É superando o dado em direção ao campo dos possíveis e realizando uma possibilidade entre todas que o indivíduo se objetiva e contribui para fazer a história: seu projeto toma, então, uma realidade que o agente talvez ignore e que, pelos conflitos que ela manifesta e que engendra, influencia o curso dos acontecimentos (SARTRE, 1960/1978, p. 153).

O projeto, portanto, não é um acontecimento que o sujeito toma consciência em determinado momento de sua vida, como uma coisa diferente dele, pelo contrário, o projeto acontece no plano do vivido, resulta no/do próprio sujeito, pois é sobre o projeto que o sujeito se constitui - mesmo se esse projeto for alienado ou for vivido no plano de uma reflexão não posicional de si.

O projeto existe desde que o sujeito é lançado no mundo e se encontra condicionado a todas as suas experiências vividas, as quais oferecem um contorno ou uma coloração particular que resultará no diferencial entre o projeto de um sujeito e de outro sujeito. É uma totalidade de sínteses dialéticas de superações e conservações de aprendizagens passadas e presentes em favor de um futuro. Caracterizado por ser dinâmico, o projeto é sempre atualizado, e se constitui num movimento de totalizações, retotalizações e destotalizações incessantes (PRETTO, 2003).

É por causa disso que Sartre fala que a vida desenvolve-se em espiral. Não há como apagar o que aconteceu no passado, mas há como resignificar, sendo justamente esse resignificar que nos faz voltar sempre aos mesmos pontos e fazer novas sínteses, num movimento de totalização e retotalização, em direção ao futuro que projetamos. 
Tais significações são totalidades históricas sintéticas, não são isoladas, ocorrem integradas na experiência de ser. Por meio de um movimento dialético e não excludente, alteram-se e formam novas sínteses, num único ato. Por isso, ao sermos adultos, a criança que fomos não desaparece, ainda nos constitui, e como vivemos numa temporalidade, o velho que queremos ser, também já nos habita (BEAUVOIR, 1990). Assim, "cada significação transforma-se, não cessa de se transformar e sua transformação repercute sobre todas as outras" (SARTRE, 1960/1978, p.160).

Outro aspecto importante quanto ao projeto, é o campo de instrumentos (teóricos e práticos) disponíveis/possíveis que o sujeito pode utilizar para constituí-lo. Estes são fundamentais, podendo tanto dos desviar de nosso projeto inicial, promovendo sofrimento, ou nos levar ao encontro dele, possibilitando realização existencial, ou ainda, podendo imprimir a possibilidade de alteração do projeto inicial. Assim,

[...] a substituição de um determinado projeto por outro representa um rompimento no continuum da temporalidade. Esse rompimento deriva da rearticulação da unidade sintética de possibilidades que constitui o projeto. A possibilidade de alterar radicalmente o projeto - isto é, de substituí-lo - está permanentemente aberta à realidade humana (BURDZINSKI, 1999, p. 83).

Isto implica em que a vivência concreta do sujeito é vivência de uma época, por isso se dá em meio a contradições, rearranjos, reconfigurações, oposições, concomitâncias, a partir de uma multiplicidade de perspectivas. O sujeito a significa singularmente a partir de sua história, organizando de forma unificada as variadas significações coletivas, tornando-se um sujeito único, com uma coloração específica em seu projeto.

Por isso, para entender um sujeito ou uma situação, deve ser buscada a sua especificidade histórica, restituindo-lhe suas funções e suas múltiplas dimensões, evitando assim o risco de cairmos na generalidade, onde todos os sujeitos devem ser iguais e atender a mesmos ditames dentro de sistemas ou modos de ser hegemônicos. Estes, por sua vez, implicam na não passagem pela singularidade do sujeito, tornando-a vazia e reduzindo-a a uma universalidade abstrata e descontextualizada.

Para compreender e analisar o sujeito, Sartre propõe uma saída do abstrato para o concreto, buscando evitar as significações idealistas para recolocar o homem no seu quadro histórico, entendendo quais os instrumentos e o campo de possíveis em cada época e num contexto existencial específico.

Considerando a realidade concreta em constante movimento dialético, Sartre formula um método que objetiva contemplar o movimento singular/universal da constituição humana, a partir de descrições e compreensões fundadas numa totalização em curso. Tal método foi chamado pelo autor de "progressivo-regressivo". 


\section{O MOVIMENTO PROGRESSIVO REGRESSIVO E A PESQUISA}

O movimento progressivo-regressivo se constitui como uma forma de compreender o sujeito, na medida em que busca se amparar em análises que percorrem as sínteses totalizadoras, tanto das singularidades como do coletivo. Visa o movimento de totalização histórica da singularidade na intersecção da totalidade histórica geral, uma esclarecendo a outra, ambas imbricadas, porém irredutíveis,

$$
\begin{aligned}
& \text { [...] pois a totalidade dialética deve envolver os atos, as } \\
& \text { paixões, o trabalho e a necessidade, tanto quanto as categorias } \\
& \text { econômicas; ela deve colocar ao mesmo tempo, o agente ou } \\
& \text { o evento no conjunto histórico, definindo-o em relação à } \\
& \text { orientação do futuro, e determinar exatamente o sentido do } \\
& \text { presente enquanto tal (MACIEL, 1986, p. 164). }
\end{aligned}
$$

Ao buscarmos o duplo movimento que vai da singularidade à universalidade, retornando a esta singularidade, sempre dentro da perspectiva histórica (passado/ futuro), podemos estabelecer uma síntese horizontal, que é relativa à temporalidade, e uma vertical, relativo a singularidade na multiplicidade (MAHEIRIE, 1994).

A compreensão, diferente de algo abstrato e isolado, ocorre concretamente, sendo um momento da práxis que transforma tanto o objeto como o sujeito que o estuda, situando-os em sua condição objetiva e subjetiva de devir. Na medida em que a condição humana é entendida como dialética, torna-se impossível ao pesquisador ausentar-se da relação com o seu objeto. Nesse sentido, para garantir a objetividade da pesquisa, os princípios ou a perspectiva teóricometodológica da qual o pesquisador parte, devem ser elucidadas e compreendidas como parte da pesquisa.

Para a elaboração da compreensão são necessários dois momentos específicos. O primeiro da cumplicidade ou analítico regressivo, e o segundo, da criticidade ou histórico genético. A descrição fenomenológica é fundamental para a efetivação do método. Partindo da premissa de que ser e aparecer são a mesma coisa, a descrição tem por finalidade trazer a tona a situação do ponto de vista do sujeito que a retrata, contextualizando-a na existência do mesmo com toda sua significação e vivência. Resulta num exercício de "olhar com o olhar do outro", o que, ao mesmo tempo, esclarece para o sujeito e para o pesquisador o fenômeno vivido.

Segundo Maheirie (1994), a compreensão cúmplice parte da racionalidade do próprio sujeito, sua inteligibilidade e os fatos históricos vividos por ele. A compreensão crítica por sua vez, implica vislumbrar outras possibilidades diferentes daquelas escolhidas pelo sujeito em sua história, bem como a elucidação do caminho que percorreu, instrumentos de reflexão ou de alienação que lançou mão e que caracterizaram seu movimento vivido.

A realização da compreensão nestes termos, pode estar permitindo um futuro aberto para o sujeito. Isto quer dizer que os sujeitos e as situações históricas podem se fazer diferentes do que são, já que considerar a temporalidade e a mudança, pode estar ampliando suas possibilidades de ser no mundo. Tal postura 
tende a evitar reducionismos e certo conformismo com realidades as quais visam submeter o sujeito a acreditar no caráter a-histórico de sua constituição singular e da realidade na qual está inserido.

Para finalizar, é importante lembrar que, na pesquisa, a dialética teoria/ prática necessita ser mantida na análise da realidade. A teoria tem a função de elucidar a prática e a prática de elucidar a teoria. O movimento dialético entre as duas esferas precisa ser considerado como garantia de não cristalizações, bem como de superações constantes em direção a compreensões mais adequadas, a partir de contextos históricos específicos.

\section{Notas}

1 Na perspectiva de Sartre, ontologicamente o homem é corpo e consciência (SARTRE, 1943/2001), sendo esta sinônimo de subjetividade, a qual constitui-se por ser pura relação, precisando do outro para existir e para significar, ou seja, para constituir-se através da objetividade numa subjetividade objetivada. Nesse sentido, o sujeito é liberdade por princípio, quer dizer, transcende o determinismo da natureza, pois diferentemente de outros animais, o homem está por se fazer.

\section{REFERÊNCIAS}

BEAUVOIR, S. A Belice (1970). Tradução Maria Helena Franco Martins. Rio de Janeiro: Nova Fronteira, 1990.

BURDZINSKI, J. C. Má-fé e Autenticidade: um breve estudo acerca dos fundamentos ontológicos da má-fé na obra de Jean Paul Sartre. Ijuí, RS: UNIJUÍ, 1999.

MACIEL, L C. Sartre: vida e obra. 5. ed. São Paulo: Paz e Terra, 1986.

MAHEIRIE, K. Agenor no Mundo: um estudo psicossocial da identidade. Florianópolis: Letras Contemporâneas, 1994. Coleção Teses.

. Constituição do sujeito, subjetividade e identidade. Revista Interações, São Paulo, v. 7, n. 13, p. 31-44, jan./jun. 2002.

PRETTO, Z. Como tecer a mais antiga/contemporânea trama: significações de amor segundo homens jovens universitários. Dissertação (Mestrado)Universidade Federal de Santa Catarina, Florianópolis, 2003.

SARTRE, J. P. Em Defesa dos Intelectuais (1972). Tradução Sérgio Góes de Paula. São Paulo: Ática, 1994.

Pensadores).

. Questão de Método (1960). São Paulo: Abril Cultural, 1978. (Os . O Ser e o Nada: ensaio de fenomenologia ontológica (1943). Tradução e notas de Paulo Perdigão. 10. ed. Rio de Janeiro: Vozes, 2001. 
Recebido em: abril de 2006

Aceito em: setembro de 2007 